nor his former promise was ever realised. He avoided public discussion, whil as it now appears he privately depreciated results incompatible with his own. To Archdeacon Pratt I am grateful for producing evidence of the kind of weapon which I had long suspected to have been employed by my distinguished adversary.

Jublin, July I

\section{Oceanic Circulation}

Mr. LAUGHTON treats an experiment which was only intended to be illustrative as if it had been advanced as probative, and tests it by a doctrine of "thermometric gradients" which does not correspond to the facts of the case. A uniform reduction of the temperature of ocean-water from the Equator to the Pole would doubtless give a "thermometric gradient" of infinitesimal minuteness. But the water of the circumpolar area, on which what Sir John Herschel truly designated the intense action of polar cold is exerted, brings with it so much of equatorial heat that a very decided increase of its specific gravity must be produced by the cooling process to which it is subjected within the polar area. This increase will be adequate, as I have attempted to show, to produce a continuous downward movement of the whole mass of water subjected to the conling process; and such a movement, however slow, will make itself perceptible in a continuous outflow of the chilled dense water along the deepest floors of the great oceanic basins, and in a continuous indraught of warmer surface water into the polar area. The proof that such is the case seems to me to be afforded by the fact that temperatures not much above $32^{\circ}$ seem to be uniformly met with at depths exceeding 2,000 fathoms, even under the equator; a fact of which Mr. Langhton and those who think with him have not, so far as $I$ am aware, offered any account. That there is nothing in depth, per se, which produces this depression is shown by the absence of it in the Mediterranean.

It would be difficult, if not impossible, to carry out a probative experiment that should represent the actual conditions of the case. Taking the distance from the pole to the equator at 6,250 iniles, and the average depth to which the chilled water would descend at $2 \frac{x}{2}$ miles, we should require a trough having a proportion of 2,500 to $x$ between its length and its depth, or (in round numbers) a length of half a mile to a depth of a foot. Let it be supposed that cold were continuously applied by a powerful freezing mixture to the surface of the water occupying one extremity of the trough as far as one-tenth of its length, and that heat were applied to the surface of the water occupying the opposite extremity to a corresponding extent, the intervening water being neither heated nor cooled artificially, would, or would not, a continuous circulation from the one end of the trough to the other come to be established? 'To me it seems that what Sir John Herschel calls the "common sense of the matier" teaches that the continuous descending movement given to the water at the polar end of the trough must in time propagate itself to the equatorial, provided only that the conducting power of the sides and floor of the trough were sufficiently bad to prevent the chilled stratum which falls to the bottom at one end from losing its cold before it reaches the other.

When such masters of Thermotics as Pouillet and Herschel consider that the doctrine of a general oceanic circulation sustained by differences of temperature is conformable to the facts at present known, I would suggest whether it would not be wise if those who are interested in the subject, instead of attempting to controvert their views on theoretical considerations, were to use their endeavours to collect additional data for practically testing them. By the kindness of the Hydrographer to the Admiralty I hope, in the course of the present season, to obtain some further information of a reliable kind; and I am doing my utmost to urge upon our Government a systematic inquiry into what the Secretary of the Scottish Meteorological Society has truly designated (in a recent letter to me) as "the most important problem in Terrestrial Physics."

July 3

\section{WILIIAM B. CARPEN'TER}

I sHovld need Mr. Laughton's hint if I had ever supposed that the cause of the vertical circulation of the ocean could be determined by such an experiment as I suggested. The experiment was specially intended to throw light on the easterly and westerly oceanic movements. For this purpose it is only necessary that the rate of rotation of the shallow cylinder should be duly adjusted to the observed rate of the vertical_motions. But even in this respect the experiment would afford but an illustration, not a demonstration.

The subject of oceanic circulation is altogether too wide and too difficult for discussion in letters. Every point touched on by Mr. Laughton requires many columns for its full discussion. I just note that the infinitesimal nature of the thermometric gradients scarcely seems a sounder objection to the temperature theory of oceanic circulation than to the temperature theory of atmospheric circulation. In one case, as in the other, we must integrate the effects of the solar light on tropical and subtropical regions. RICHARD A. Proctor

\section{Day Auroras}

LAST evening, about eight o'clock, being in the grounds belonging to the Radcliffe Observatory, I was exceedingly surprised at seeing what I have no doubt of being true auroral streamers, forming a little to the east of the south meridian, reaching an altitude of about $25^{\circ}$, and after travelling some distance in a westerly direction, vanishing. This lasted at least ten minutes, when the sky, which had been overcast nearly all day again became so. I pointed the streamers out to several people who were near me, some of whom watched them with me, as a proof of what I had before doubted, namely, that auroras are visible by daylight. JOHN LUCAS,

Radcliffe Observatory, Oxford, June 28

Assistanl at Radcliffe Observatory

\section{The Solar Parallax}

I REGRET that I have misinterpreted the severity of Prof. Newcomb's remarks respecting my chapter on the Solar Parallax, The fact is, that so far back as February $\mathrm{I} I$ was warned by an eminent astronomer that Prof. Newcomb had vowed here last November that he would annihilate all who upheld the finality or correctness of Mr. Stone's researches.

Prof. Newcomb must be sensible that his offer to supply information as to the history of inquiries into the solar parallax during the last few years is a very generous one; and that it will be immensely to my advantage to profit by his exceptional familiarity with the subject. I thank him very earnestly. I have an especial distaste for inquiries into the historical parts of scien. tific subjects, and shall rejoice to be saved the labour of looking up authorities, \&c., in this particular matter. If I find my account requires alteration, I shall admit the fact without a particle of hesitation. It is indeed most desirable (though not, perhaps, for students of science, for whom I specially write, and who need trouble themselves little on the matter that to each worker in the subject of the solar parallax his due proportion of credit should be assigned; and as in this case not only I, but Sir John Herschel, as well as the Council of the Astronomical Society, would seem to have done Prof. Newcomb less than justice, the sooner recantation is made the better.

Prof. Newcomb refers to "the kind spirit in which $I$ have taken his remarks ;" meaning rather, perhaps, the appreciative way in which I have spoken of his labours. His critique, regarded as a whole, was not, I take it, kindly meant; and though I by no means feel annihilated by it, I should be speaking untruly if I seemed to admit its justice. If I failed to note how I viewed his comments, it was only because I found a pleasanter subject to speak about in those important researches whereby he has advanced astronomy. RICHARD A. Proctor

P.S.-I take this opportunity of noting that the remark in my former letter respecting the work of $\mathrm{Mr}$. De La Rue and $\mathrm{F}$. Secchi in 1860 must not be understood as implying that the account in F. Secchi's book $L e$ Soleil is incorrect. On the contrary, I have no doubt it is strictly accurate. I was fortunate in securing a copy of $L e$ Soleil before Paris was beleaguered, and derived consi. derable assistance from its perusal.

\section{Lee Shelter}

Perhaps it is worth noting that a lee shelter is almost as effectual as a screen to the windward. The fact may be quite well known and understood; but I did not become aware of it till I was on Bognor Pier, when a strong gale was blowing directly on the broadside. There are seats backed and covered overhead and on the sides, alternately, on the one or other side of the pier, and on this occasion all the seats to the windward were occupied, so that, wanting a rest, $I$ had to put up with one 